\title{
Análise da rotulagem de bebidas mistas de frutas e vegetais denominadas detox
}

\section{Labeling analysis of mixed fruit and vegetable drinks called detox}

\author{
Eliane Beatriz Magalhães Silva',* (iD \\ Valéria Regina Martins Vieira"'I iD \\ Simone Aparecida Rodrigues de \\ Oliveira Gonçalves"II (iD) \\ Jacqueline Aparecida Takahashi" iD \\ Raquel Linhares Bello de Araújo'
}

\section{RESUMO}

Introdução: Os rótulos fornecem informações para a orientação do consumidor sobre as escolhas alimentares mais adequadas às suas necessidades, sendo um importante canal de comunicação entre o consumidor e o produtor de alimentos. Para cumprir esse papel, é fundamental que essas estejam corretas e atendam aos parâmetros legais estabelecidos. Objetivo: Avaliar a conformidade dos rótulos das bebidas mistas industrializadas à base de frutas e vegetais que apresentavam a denominação suco detox, comercializadas em Belo Horizonte (MG), Brasil, entre os anos de 2017 e 2019. Método: Foram selecionadas inicialmente 23 bebidas mistas e, após a avaliação dos critérios de exclusão, sete amostras de diferentes marcas foram selecionadas para o estudo. A análise da rotulagem foi realizada conforme a regulamentação vigente para alimentos na legislação brasileira, utilizando um checklist com os seguintes itens obrigatórios: denominação do produto; lista de ingredientes; conteúdo líquido; identificação de origem; identificação de lote; prazo de validade; cuidados de conservação; uso de frases e imagens que podem causar erro ou engano ao consumidor; rotulagem nutricional; advertência sobre o glúten e o número do registro das bebidas no Ministério da Agricultura e Pecuária e Abastecimento (MAPA). Resultados: Em 100\% $(n=7)$ das amostras foi observada a irregularidade do uso do termo detox nos rótulos e ausência do registro junto ao MAPA. Setenta por cento $(n=5)$ apresentavam erros na lista de ingredientes e informação nutricional e em $57 \%(n=4)$ não estava correta a informação do conteúdo líquido. Conclusões: Os resultados evidenciaram a presença de não conformidades em todos os produtos analisados. Destacaram-se as irregularidades em relação à denominação de venda e a ausência de registro. Diante disso, enfatiza-se a necessidade de adequação das empresas frente à regulação da rotulagem dos alimentos e a importância de se promover ações que permitam aos consumidores acesso a informações confiáveis sobre esses alimentos.

PALAVRAS-CHAVE: Alimentos Embalados; Legislação de Alimentos; Rotulagem

\section{ABSTRACT}

Introduction: Labels provide information to guide consumers about the most appropriate food choices for their needs, being an important channel of communication between the consumer and the food producer. To fulfill this role, it is essential that these are correct and meet the established legal parameters. Objective: To evaluate the conformity of labels of industrialized mixed drinks based on fruits and vegetables that had the name "detox juice", in products marketed in Belo Horizonte, Minas Gerais (MG), Brazil, between the years 2017 and 2019. Method: 23 mixed drinks were initially selected and after evaluating the exclusion criteria, seven samples of different brands were included in this study. The analysis of the labeling was carried out according to the current regulation for food in Brazilian legislation, using a checklist with the following mandatory items: product name; list of ingredients; liquid content; origin identification; batch identification; expiration date; conservation care; use of phrases and images that may cause errors or mistakes to the consumer; nutritional labeling; warning about gluten and the registration number of beverages at the Ministry of Agriculture and Livestock and Supply (MAPA). Results: In $100 \%(n=7)$ of the samples, irregularity in the use of the term "detox" on the labels and 
absence of registration with MAPA were observed. In 70\% $(n=5)$ they had errors in the list of ingredients and nutritional information and in $57 \%(n=4)$ the information on the liquid content was not correct. Conclusions: The results showed the presence of non-conformities in all the analyzed products. The irregularities in relation to the sales denomination and the absence of registration were highlighted. In view of this, it is emphasized the need for companies to adapt to the regulation of food labeling and the importance of promoting actions that allow consumers access to reliable information about these foods.

KEYWORDS: Packaged Food; Food Legislation; Labeling

\section{INTRODUÇÃO}

A rotulagem dos alimentos é um instrumento de comunicação entre o produtor e o consumidor e possibilita compreender a composição do alimento, podendo contribuir também para as escolhas alimentares mais saudáveis. 0 principal objetivo da rotulagem é apresentar a composição do alimento e suas características nutricionais ${ }^{1,2,3}$. Por meio dela, os profissionais de saúde também podem orientar de forma mais adequada sobre a composição das dietas, mas, para isso, é importante que as informações presentes nos rótulos sejam fidedignas, com linguagem clara, precisa e ostensiva e que respeitem as obrigatoriedades das legislações ${ }^{4,5,6}$. A legislação brasileira apresenta a rotulagem de alimentos dividida em rotulagem geral, que é definida como toda a informação presente no rótulo do alimento e a rotulagem nutricional, que consiste na descrição destinada à informação das propriedades nutricionais do produto alimentício?

O controle sanitário de alimentos no Brasil é realizado por um conjunto de órgãos, composto pelo Ministério da Saúde (MS), por meio da Agência de Vigilância Sanitária (Anvisa); o Ministério da Justiça; o Ministério da Agricultura, Pecuária e Abastecimento (MAPA) e o Instituto Nacional de Metrologia, Qualidade e Tecnologia (Inmetro).

A Anvisa tem por finalidade promover a proteção da saúde da população, por intermédio da regulamentação, fiscalização e controle sanitário da produção e da comercialização de produtos e serviços submetidos à vigilância sanitária. Entre esses produtos estão: alimentos, bebidas, águas envasadas, seus insumos, suas embalagens, aditivos alimentares, limites de contaminantes orgânicos, resíduos de agrotóxicos e de medicamentos veterinários ${ }^{8}$.

As principais legislações que estabelecem as rotulagens geral e nutricional são: Decreto-Lei n 986, de 21 de outubro de 1969, que institui normas básicas sobre alimentos"; a Resolução da Diretoria Colegiada (RDC) $n^{\circ} 259$, de 20 de setembro de 2002, que dispõe sobre o regulamento técnico para rotulagem de alimentos embalados; a RDC ${ }^{\circ}$ 359, de 23 de dezembro 2003, que dispõe sobre o regulamento técnico de porções de alimentos embalados para fins de rotulagem nutricional e a $\operatorname{RDC} n^{\circ} 360$, de 23 de dezembro de 2003, que dispõe sobre regulamento técnico sobre rotulagem nutricional de alimentos embalados ${ }^{4}$. Outras legislações são obrigatórias e devem ser observadas pelo fabricante em sua rotulagem, como a RDC $\mathrm{n}^{\circ} 26$, de 2 de julho de $2015^{10}$ (alergênicos), que determina o que deve conter no produto para que este alimento apresente alegações obrigatórias dos principais alimentos que causam alergias. Posteriormente, em 2017, a RDC ${ }^{\circ}$ 136, de 8 de fevereiro ${ }^{11}$, regulamentou a declaração obrigatória para produtos lácteos (lactose).
As alegações de propriedade nutricional ou de saúde em um alimento podem fazer referência à manutenção geral da saúde, ao papel fisiológico dos nutrientes e não podem sugerir a cura ou a prevenção de doenças de acordo com a RDC $n^{\circ} 259 / 2002^{12}$.

O MAPA possui a atribuição de regulamentação e fiscalização de bebidas e produtos de origem animal. 0 Decreto $\mathrm{n}^{\circ} 6.871$, de 4 de junho de $2009^{13}$, que regulamenta a Lei $n^{\circ} 8.918$, de 14 de julho de 1994, dispõe sobre a padronização, a classificação, o registro, a inspeção, a produção e a fiscalização de bebidas. Existem diferentes tipos de bebidas, dentre elas: sucos concentrados, desidratados e néctares, que são produzidos pela diluição da parte comestível do vegetal ou de seu extrato em água potável, sendo adicionados de açúcares. Outro tipo de bebida é o refresco obtido pela diluição, em água potável, do suco de fruta, polpa com ou sem adição de açúcares. Quando a bebida for adicionada de açúcares, deverá ter a designação adoçado, acrescida à sua denominação de venda ${ }^{13}$.

A bebida mista é obtida a partir da mistura de duas ou mais frutas ou vegetais. A denominação do produto deve ser seguida da relação das frutas e vegetais utilizados, em ordem decrescente das quantidades presentes na mistura, sendo considerado infração produzir, fabricar, manipular e comercializar bebidas sem registro junto ao MAPA ${ }^{13}$. As Instruções Normativas (IN) $n^{\circ} 17^{14} e^{\circ}{ }^{\circ} 19^{15}$, de 19 de junho de 2013, estabelecidas, tornaram obrigatório especificar a proporção utilizada de suco de fruta, suco vegetal ou polpa de fruta, cuja presença foi informada no rótulo, além de estabelecer o percentual mínimo obrigatório de frutas nas bebidas.

Desta forma, os consumidores que buscam alternativas de bebidas com maior concentração de sucos e redução de açúcares adicionados podem fazer a escolha adequada, nesse contexto, os sucos mistos ou blends são opções que apresentam demanda de mercado ${ }^{16}$, assim como as bebidas mistas denominadas detox.

O termo detox é uma redução da palavra de origem inglesa detoxication, que significa desintoxicação em português, o que elimina toxinas, entretanto, não há evidências científicas que possam comprovar a atribuição do termo detox ao alimento. Desta maneira, torna-se importante que ocorra a fiscalização dos produtos industrializados e também o cumprimento da legislação pelos fabricantes ${ }^{13}$.

Segundo Ferrazeri et al. ${ }^{1}$, existem lacunas na legislação que favorecem a comercialização e interpretação equivocada do consumidor e/ou do produtor, e possibilitam a introdução de sucos não regulamentados no mercado. Isso é agravado pelas sucessivas 
alterações nas normas e pela falta de padronização da terminologia empregada, bem como pela ausência de definições essenciais, dificultando a consulta e o conhecimento da legislação.

De acordo com o Art. 21 do Decreto-Lei ${ }^{\circ} 986 / 1969^{9}$ e a RDC $n^{\circ} 259 / 2002^{12}$ no item 3.1 , os rótulos não podem conter vocábulos, denominações que possam induzir o consumidor ao erro/ engano. Diante do exposto, o objetivo deste estudo foi avaliar a adequação frente às legislações vigentes da rotulagem de bebidas mistas de frutas e vegetais que apresentavam a denominação detox nos rótulos.

\section{MÉTODO}

Trata-se de um estudo observacional, descritivo, transversal e qualitativo, no qual foi avaliado o cumprimento das informações contidas em rótulos de bebidas mistas de acordo com as legislações vigentes pertinentes ao tipo de amostra selecionada. As amostras foram adquiridas pela internet ou compradas no comércio do município de Belo Horizonte, estado de Minas Gerais. O estudo foi realizado no período de 2017 a 2019. Os rótulos foram analisados pela equipe técnica do Serviço de Análise de Rotulagem da Fundação Ezequiel Dias (Funed), em parceria com a Universidade Federal de Minas Gerais (UFMG).

Foram selecionadas 23 amostras de bebidas mistas de frutas e vegetais que apresentavam no rótulo a denominação detox. Após a primeira verificação dos rótulos, 16 amostras foram excluídas por não respeitavam os critérios estabelecidos através das legislações vigentes, tais como: a ausência da tabela nutricional $(n=5)$, alteração da denominação de venda $(n=3)$, a indicação da adição de minerais na composição $(n=5)$ e a descontinuidade de venda $(n=3)$.

Foram intituladas A, B, C e D "pó para preparo de refresco", as amostras de polpa congelada foram a $\mathrm{E}$ e $\mathrm{F}$ e a amostra $\mathrm{G}$ correspondia à "bebida pronta para o consumo".
A análise de rotulagem foi realizada conforme a legislação brasileira vigente, com base nas regulamentações. Para o estudo da conformidade foi utilizado um checklist para verificação dos itens obrigatórios e para análise dos rótulos, listados no Quadro 1.

Após a verificação dos parâmetros acima descritos, o rótulo que apresentou pelo menos uma não conformidade (NC) em relação ao cumprimento da legislação foi considerado insatisfatório.

\section{RESULTADOS E DISCUSSÃO}

De acordo com o observado na Figura, as irregularidades presentes nos rótulos variaram entre $36 \%$ (marca $C)$ a $79 \%$ (marca F).

A amostra $\mathrm{F}$ apresentou o maior percentual de irregularidades, foi verificada a presença de NC em 11 itens obrigatórios. Em seguida, a amostra $E$ apresentou oito $N C$ e as amostras A, B, D e G, seis NC. A amostra C apresentou cinco não conformidades.

Outros estudos que avaliaram as irregularidades com relação à rotulagem em bebidas, também encontraram diferentes percentuais de NC, tais como: $28 \%$ em vinhos nacionais ${ }^{21}, 77 \%$ em néctares de $u^{22} a^{22}$ e $33 \%$ em polpas de açaíi ${ }^{23}$. Além de bebidas, podemos citar que diferenças de NC também se destacam nos mais variados produtos disponíveis ao consumidor, a exemplo de: $90 \%$ em produtos destinados ao público infantil ${ }^{24}, 95 \%$ em marcas de pão de forma ${ }^{25}, 86 \%$ em massas frescas ${ }^{26}, 91 \%$ em barras de cereais light $^{27}, 97 \%$ em iogurtes ${ }^{28} \mathrm{e}$, em diferentes categorias de alimentos, $81 \% 29$.

No Quadro 2, estão relacionadas as amostras avaliadas e os itens não atendidos. Dentre os itens avaliados, destaca-se a NC em $100 \%$ das amostras nos quesitos: denominação de venda, declarações, figuras, símbolos, desenhos e ausência do registro junto ao MAPA.

Quadro 1. Legislação, ementa e parâmetros avaliados no estudo.

\begin{tabular}{|c|c|c|}
\hline Legislação & Ementa & Parâmetro avaliado \\
\hline Lei $\mathrm{n}^{\circ} 10.674$, de 16 de maio de $2003^{17}$ & $\begin{array}{l}\text { Informação sobre a } \\
\text { presença do } \\
\text { glúten }\end{array}$ & Advertência - Glúten \\
\hline $\begin{array}{l}\text { RDC } n^{\circ} 259 / 2002 d a \\
\text { Anvisa/MS }\end{array}$ & $\begin{array}{l}\text { Rotulagem geral } \\
\text { obrigatória }\end{array}$ & $\begin{array}{c}\text { Denominação do produto, Lista de ingredientes/aditivos, Identificação } \\
\text { da origem, Identificação do lote } \\
\text { Prazo de validade } \\
\text { Instrução sobre preparo/uso } \\
\text { Apresentação e distribuição das informações obrigatórias } \\
\text { Cuidados de conservação } \\
\text { Declarações/figuras/símbolos/desenhos que podem causar confusão/ } \\
\text { erro/engano }\end{array}$ \\
\hline $\begin{array}{l}\mathrm{RDC} \mathrm{n}^{\circ} 359 / 2003 \mathrm{da} \\
\text { Anvisa/MS }\end{array}$ & Porção alimentar & $\begin{array}{c}\text { Porção } \\
\text { Medida caseira }\end{array}$ \\
\hline $\begin{array}{l}\mathrm{RDC} \mathrm{n}^{\circ} 360 / 2003 \mathrm{da} \\
\text { Anvisa/MS }{ }^{19}\end{array}$ & $\begin{array}{l}\text { Rotulagem } \\
\text { nutricional }\end{array}$ & Informação nutricional \\
\hline $\begin{array}{l}\text { Portaria } \\
n^{\circ} 157 / 02 / \text { Inmetro } 20\end{array}$ & $\begin{array}{l}\text { Conteúdo } \\
\text { líquido }\end{array}$ & $\begin{array}{c}\text { Apresentação da indicação quantitativa do } \\
\text { conteúdo líquido }\end{array}$ \\
\hline $\begin{array}{l}\text { Decreto } n^{\circ} 6.871 / 2009 \text {, que regulamenta a } \\
\text { Lei } n^{\circ} 8.918 \text { de } 1994^{13}\end{array}$ & Registro da bebida & $\begin{array}{l}\text { Número e validade do registro Características do padrão de identidade e } \\
\text { qualidade do produto }\end{array}$ \\
\hline
\end{tabular}

Fonte: Elaborado pelos autores, 2019.

RDC: Resolução da Diretoria Colegiada; Anvisa: Agência Nacional de Vigilância Sanitária; Inmetro: Instituto Nacional de Metrologia, Qualidade e Tecnologia. 


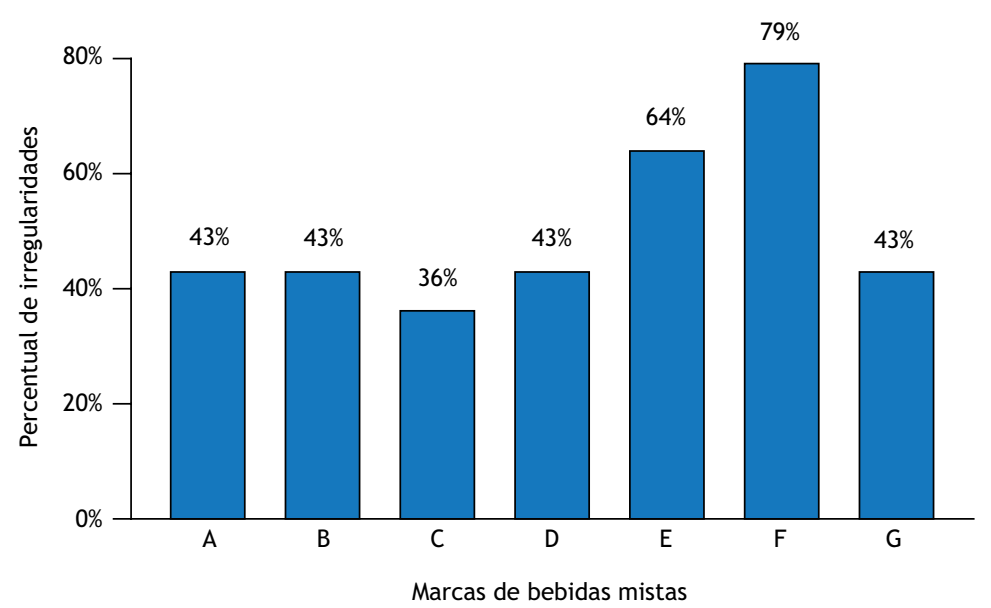

Fonte: Elaborado pelos autores, 2019.

Figura. Percentual de irregularidades verificadas nas marcas de bebidas mistas analisadas. Amostras: A, B, C e D (pó para preparo de refresco); E e F (polpa congelada) e G (bebida pronta).

Em relação ao item "Denominação de venda", todas as amostras estavam irregulares por divergência dos critérios previstos na legislação. No requisito da "Lista de ingredientes", 71\% dos rótulos apresentaram-se não conformes. Por serem bebidas mistas de frutas e vegetais em que não se sabe o peso de cada componente, deveria constar na lista de ingredientes a seguinte expressão "em proporção variável” quando se tratar de alimentos desidratados, que necessitam de reconstituição para seu consumo pela adição de água, os ingredientes podem ser enumerados em ordem de proporção $(\mathrm{m} / \mathrm{m})$ no alimento reconstituído. Além disso, deve-se incluir a expressão "ingredientes do produto preparado segundo as indicações do rótulo".

No presente estudo, a ausência das informações sobre "Identificação de origem" e "Identificação de lote" foi uma irregularidade observada em $43 \%$ e $29 \%$ das amostras, respectivamente. A legislação caracteriza como origem do produto o nome do fabricante, endereço, país de origem e município. Carneiro et al. ${ }^{22}$ avaliaram diferentes amostras de néctares relatando que apenas $43 \%$ das amostras analisadas informaram o conteúdo líquido e o lote de fabricação. Outros autores encontraram valores menores que o do presente estudo. Grandi e Rossi ${ }^{28}$ não localizaram a identificação do lote em $16 \%$ de rótulos de iogurtes e em $25 \%$ de rótulos de bebidas lácteas fermentadas. Já Pereira et al. ${ }^{30}$ relataram tal irregularidade em $16 \%$ dos rótulos de barras de cereais e pães light, valor menor do que no presente estudo.

Em 29\% dos sucos não havia informações referentes ao "Prazo de validade" e, em relação ao "Modo de conservação", 43\% dos rótulos estavam irregulares. A legislação exige no mínimo mês e ano para indicar a data de validade, modo de conservação e armazenamento do produto antes e depois de aberto. No caso de polpas congeladas, estas não apresentavam a indicação de temperatura de conservação do produto. Mello et al..$^{24}$ constataram que em $28 \%$ dos alimentos não havia informações sobre modo de conservação após aberta a embalagem, indicação do fabricante sobre temperatura de conservação de alimentos refrigerados e $3 \%$ dos rótulos não apresentaram data de validade. Yamashita e Carrijo ${ }^{31}$, estudando patês, encontraram 31\% de não conformidade em relação à falta da publicação de informação para armazenamento do produto depois de aberto.

Foram encontrados em $100 \%$ dos rótulos "Vocábulos, sinais e denominações" que podem induzir o consumidor a erro. Além do termo detox podem ser destacadas as seguintes frases: " $100 \%$ natural" e "equilíbrio e sabor", "é saudável e saboroso", "ajuda eliminar toxinas do organismo", "alimente esse hábito saudável", "natural é viver bem", ressalta-se que esses termos atribuem valores ao alimento que não são verdadeiros. Mello et al. ${ }^{24}$ encontraram esse tipo de irregularidade em $85 \%$ dos rótulos de 18 categorias de produtos infantis, sendo que os maiores percentuais de irregularidades foram frutas, picolés, sucos à base de soja e leites fermentados. Pereira et al. ${ }^{30}$ constataram $54 \%$ de irregularidades neste item em barras de cereais e pães light. Smith e Almeida-Muradian ${ }^{29}$ avaliaram 13 categorias de produtos alimentícios, sendo que $30 \%$ apresentaram a mesma irregularidade. Barros e Batista ${ }^{27}$ apresentaram valores inferiores de irregularidades (20\%) em rótulos de barra de cereais light. Santos et al. ${ }^{32}$ encontraram irregularidade em $25 \%$ dos rótulos de goma de tapioca sobre informações dos nutrientes obrigatórios da tabela nutricional, seguindo uma ordem específica sobre a disposição dos nutrientes. Já Smith e Almeida-Muradian ${ }^{29}$ encontraram resultados de $27 \%$ em análise de alimentos infantis.

Com relação à "Porção declarada" e "Medida caseira", estas não estavam corretas na amostra $G$. No rótulo da amostra $F$ foi verificada a ausência de medida caseira, totalizando 29\% de reprovação neste item. Grandi e Rossi ${ }^{28}$ relataram a ausência de medida caseira em $5 \%$ dos rótulos de iogurtes e $14 \%$ dos rótulos de bebidas lácteas estavam em desacordo com a legislação. A medida caseira é uma informação importante para o consumidor no momento das escolhas alimentares e pode ser considerada uma ferramenta para educação nutricional ${ }^{33}$.

Todos os rótulos continham indicação de "Peso líquido", mas $57 \%$ das amostras apresentaram não conformidade por não 
Quadro 2. Amostras avaliadas/itens não atendidos.

\begin{tabular}{|c|c|}
\hline Amostra & Itens não atendidos \\
\hline $\begin{array}{l}\text { A (pó para preparo de } \\
\text { refresco) }\end{array}$ & $\begin{array}{l}\text { Denominação de venda } \\
\text { Lista de ingredientes/aditivos } \\
\text { Identificação da origem } \\
\text { Declaração que podem causar erro } \\
\text { Informação nutricional } \\
\text { Número e validade do registro }\end{array}$ \\
\hline $\begin{array}{l}\text { B (pó para preparo de } \\
\text { refresco) }\end{array}$ & $\begin{array}{c}\text { Denominação de venda } \\
\text { Lista de ingredientes/aditivos } \\
\text { Conteúdo líquido } \\
\text { Declaração que podem causar erro } \\
\text { Informação nutricional } \\
\text { Número e validade do registro }\end{array}$ \\
\hline $\begin{array}{l}\text { C (pó para preparo de } \\
\text { refresco) }\end{array}$ & $\begin{array}{l}\text { Denominação de venda } \\
\text { Lista de ingredientes/aditivos } \\
\text { Conteúdo líquido } \\
\text { Declaração que podem causar erro } \\
\text { Número e validade do registro }\end{array}$ \\
\hline $\begin{array}{l}\text { D (pó para preparo de } \\
\text { refresco) }\end{array}$ & $\begin{array}{c}\text { Denominação de venda } \\
\text { Lista de ingredientes/aditivos } \\
\text { Conteúdo líquido } \\
\text { Declaração que podem causar erro } \\
\text { Informação nutricional } \\
\text { Número e validade do registro }\end{array}$ \\
\hline E (polpa congelada) & $\begin{array}{c}\text { Denominação de venda } \\
\text { Conteúdo líquido } \\
\text { Identificação da origem } \\
\text { Identificação do lote } \\
\text { Prazo de validade } \\
\text { Declaração que podem causar erro } \\
\text { Informação nutricional } \\
\text { Número e validade do registro }\end{array}$ \\
\hline F (polpa congelada) & $\begin{array}{l}\text { Denominação de venda } \\
\text { Lista de ingredientes/aditivos } \\
\text { Identificação da origem } \\
\text { Identificação do lote } \\
\text { Prazo de validade } \\
\text { Cuidado e conservação } \\
\text { Declaração que podem causar erro } \\
\text { Advertência - Glúten } \\
\text { Informação nutricional } \\
\text { Porção declarada } \\
\text { Número e validade do registro }\end{array}$ \\
\hline G (bebida pronta) & $\begin{array}{l}\text { Denominação de venda } \\
\text { Cuidado e conservação } \\
\text { Informação nutricional } \\
\text { Declaração que podem causar erro } \\
\text { Porção declarada } \\
\text { Número e validade do registro }\end{array}$ \\
\hline
\end{tabular}

Fonte: Elaborado pelos autores, 2019.

cumprirem os requisitos na forma de expressar o conteúdo nominal. Mello et al. ${ }^{24}$ constataram que $13 \%$ dos produtos infantis não apresentaram a indicação de peso líquido, sendo uma informação obrigatória. Smith e Almeida-Muradian ${ }^{29}$ encontraram 25\% de irregularidade na indicação de pesos em diferentes categorias de produtos alimentícios.

Neste estudo $14 \%$ dos rótulos estavam em desacordo com a legislação, pois não apresentavam a advertência obrigatória: "Não contém glúten". Em estudo com polpa de açaí, Fregonesi et al. ${ }^{23}$ apresentaram resultado semelhante nesse item, com $33 \%$ de rótulos incorretos. Santos et al. ${ }^{32}$ apontaram em relação a esta lei, analisando 20 diferentes amostras de goma de tapioca, e verificaram $10 \%$ de irregularidades. A lei é importante porque a doença celíaca é a intolerância alimentar mais comum no mundo, sendo necessária a exclusão de alimentos que contém o glúten da dieta de celíacos ${ }^{17,34}$.

Com relação ao item "Número e validade do registro" das bebidas junto ao MAPA, $100 \%$ das amostras não apresentavam informação de registro junto ao MAPA, ou seja, NC. O registro do produto faz parte do controle sanitário e contempla a identificação do produtor e classificação da bebida.

Todas as amostras estavam irregulares também por não apresentarem a indicação quantitativa (\% de polpa de fruta/vegetal) de acordo com as IN n $17^{14}$ e $19 / 2013^{15}$ do MAPA, ou seja, declaração no painel principal da porcentagem de polpa de suco ou vegetal, em destaque, com caracteres em caixa alta, em porcentagem volume por volume $(\mathrm{v} / \mathrm{v})$, com uma cifra decimal, de suco integral ou polpa ou o somatório destes. A bebida ou refresco misto de frutas e vegetais tem Padrão de Identidade e Qualidade (PIQ) estabelecido. 0 refresco de fruta cuja matéria-prima não está especificada deve conter uma quantidade mínima de 10\% volume por volume $(\mathrm{v} / \mathrm{v})$ de suco ou polpa da fruta. 0 refresco de vegetal cuja matéria-prima também não tem PIQ especificado deve conter uma quantidade mínima de $5 \% \mathrm{v} / \mathrm{v}$ de suco do vegetal. Apesar de esta IN ter sido publicada em 2013, não foram encontrados outros estudos que fizessem avaliação desta legislação de rotulagem de bebidas à base de frutas e vegetais ${ }^{15}$.

Conforme os resultados observados no presente estudo, os rótulos apresentavam irregularidades importantes em todas as amostras. A ausência de registro junto ao MAPA compromete a rastreabilidade do produto e a comunicação com o produtor. A falta da indicação quantitativa de percentual de fruta e vegetal no rótulo não auxilia o consumidor nas escolhas alimentares por melhores produtos. $\mathrm{E}$ o termo detox pode induzir o consumidor ao erro ao atribuir alegações que não são aprovadas pela legislação. Para alertar sobre o uso inadequado do termo, o MS, em 2016, desenvolveu um material informativo com o objetivo de orientar os profissionais da saúde para desmistificar e esclarecer dúvidas em relação à alimentação que reforça a falta de estudos científicos e da alegação funcional do termo detox. Alertaram que assim como outros sucos naturais, os sucos mistos podem ser consumidos como parte de uma alimentação saudável, entretanto é orientado que o consumo seja moderado devido à alta porcentagem de frutose nesses produtos e nos sucos mistos é aceitável a adição de outras fontes de açúcares ${ }^{35}$. As falhas apresentadas nos rótulos apontam uma falta de comprometimento do papel da rotulagem na informação e divulgação para melhoria e promoção da saúde.

\section{CONCLUSÕES}

A rotulagem dispõe de informações importantes para escolha de produtos alimentícios, e o direito do consumidor à informação clara, precisa e ostensiva não foi observado nesse estudo. Todos os rótulos avaliados apresentaram alguma irregularidade, destacando-se as não conformidades pela utilização do termo detox e também a ausência de registro junto ao MAPA. É indispensável a continuidade das ações de fiscalização e o cumprimento da legislação pelos fabricantes, a fim de que a prevenção, a promoção e a proteção à saúde se tornem efetivos para a população. 


\section{REFERÊNCIAS}

1. Ferrarezi AC, Santos KO, Monteiro M. Avaliação crítica da legislação brasileira de sucos de fruta, com ênfase no suco de fruta pronto para beber. Rev Nutr. 2010;23(4):667-77. https://doi.org/10.1590/S1415-52732010000400016

2. Nascimento C, Raupp SMM, Townsend RT, Balsan GA, Minossi V. Conhecimento de consumidores idosos sobre rotulagem de alimentos. Rev Epidemiol Control Infect. 2013;3(4):144-7. https://doi.org/10.17058/reci.v3i4.4064

3. Machado $\mathrm{PCl}$, Santos $\mathrm{AM}$, Uggioni PL, Fabri RK, Muller J. Labeling of packaged foods in Brazil: use of terms such as homemade, traditional, and the like. Rev Nutr. 2018;31(1):83-96. https://doi.org/10.5965/24473650312017002

4. Lobanco CM, Vedovato GM, Cano CB, Bastos $\mathrm{DHM}$. Fidedignidade de rótulos de alimentos comercializados no município de São Paulo, SP. Rev Saúde Pública. 2009;43(3):499-505. https://doi.org/10.1590/S0034-89102009005000020

5. Rebouças MC, Penha MFA, Cavalcante CEB, Morais ACS. Efeito da expectativa com relação às informações sobre néctar e suco tropical de caju na aceitação do consumidor. Conex Cienc Tecnol. 2017;11(4):78-84. https://doi.org/10.21439/conexoes.v11i4.877

6. Brasil. Lei № 8.078 , de 11 de setembro de 1990. Dispõe sobre a proteção do consumidor e dá outras providências. Diário Oficial União. 12 set 1990.

7. Maas IMS, Silochi RMHQ, Casaril KBPB. Rotulagem geral e nutricional de alimentos consumidos por crianças. Rev Faz Cienc. 2012;16(23):81-99.

8. Brasil. Lei № 9.782, de 26 de janeiro de 1999. Define o Sistema Nacional de Vigilância Sanitária, cria a Agência Nacional de Vigilância sanitária, e dá outras providências. Diário Oficial União. 27 jan 1999.

9. Brasil. Decreto lei № 986, de 21 de outubro de 1969. Institui normas básicas sobre alimentos. Diário Oficial União. 22 out 1969.

10. Agência Nacional de Vigilância Sanitária - Anvisa. Resolução RDC № 26, de 2 de julho de 2015. Dispõe sobre os requisitos para rotulagem obrigatória dos principais alimentos que causam alergias alimentares. Diário Oficial União. 3 jul 2015.

11. Agência Nacional de Vigilância Sanitária - Anvisa. Resolução RDC №136, de 8 de fevereiro de 2017. Estabelece os requisitos para declaração obrigatória da presença de lactose nos rótulos dos alimentos. Diário Oficial União. 9 fev 2017.

12. Agência Nacional de Vigilância Sanitária - Anvisa. Resolução RDC № 259, de 20 de setembro de 2002. Aprova o regulamento técnico sobre rotulagem de alimentos embalados. Diário Oficial União. 23 set 2002.

13. Brasil. Decreto №6.871, de 4 de junho de 2009. Regulamenta a lei № 8.918 , de 14 de julho de 1994, que dispõe sobre a padronização,a classificação, o registro, a inspeção, a produção e a fiscalização de bebidas. Diário Oficial União. 5 jun 2009.
14. Ministério da Agricultura, Pecuária e Abastecimento (BR). Instrução normativa № 17, de 19 de junho 2013. Complementação dos padrões de identidade e qualidade para bebidas. Diário Oficial União. 20 jun 2013.

15. Ministério da Agricultura, Pecuária e Abastecimento (BR). Instrução normativa № 19, de 19 de junho 2013. Complementação dos padrões de identidade e qualidade para bebidas. Diário Oficial União. 20 jun 2013.

16. Santos MVG, Abreu VKG, Lemos TO, Silva DS, Pereira ALF. Elaboração de néctar misto de uva e gengibre. Brazilian J Food Res. 2017;8(3):126-40. https://doi.org/10.3895/rebrapa.v8n3.4464

17. Brasil. Lei № 10.674 , de 16 de maio de 2003. Obriga a que os produtos alimentícios comercializados informem sobre a presença de glúten, como medida preventiva e de controle da doença celíaca. Diário Oficial União. 19 maio 2003.

18. Agência Nacional de Vigilância Sanitária - Anvisa. Resolução RDC № 359, de 23 de dezembro de 2003. Aprova regulamento técnico de porções de alimentos embalados para fins de rotulagem nutricional. Diário Oficial União. 26 dez 2003.

19. Agência Nacional de Vigilância Sanitária - Anvisa. Resolução RDC №360, de 23 de dezembro de 2003. Aprova o regulamento técnico sobre rotulagem nutricional de alimentos embalados, tornando obrigatória a rotulagem nutricional. Diário Oficial União. 26 dez 2003.

20. Ministério do Desenvolvimento, Indústria e Comércio Exterior (BR). Portaria Inmetro №157, de 19 de agosto de 2002. Aprova o regulamento técnico metrológico, estabelecendo a forma de expressar o conteúdo líquido a ser utilizado nos produtos pré-medidos. Diário Oficial União. 20 ago 2002.

21. Mazon EMA, Rossi CA, Prado MA, Cadore S. Avaliação da rotulagem de alguns vinhos brasileiros. Rev Inst Adolfo Lutz. 2012;71(2):405-9.

22. Carneiro APG, Abreu DA, Soares DJ, Costa EA, Silva LMR, Barbosa LC et al. Avaliação da rotulagem, caracterização química, físico-química e reológica de néctares de uva comercializados na cidade de Fortaleza CE. Alim Nutr. 2013;24(2):241-9.

23. Fregonesi BM, Yokosawa CE, Okada IA, Massafera G, Costa TMB, Prado SPT. Polpa de açaí congelada: características nutricionais, físico-químicas, microscópicas e avaliação da rotulagem. Rev Inst Adolfo Lutz. 2010;69(3):387-95.

24. Mello AV, Abreu ES, Spinelli MGN. Avaliação de rótulos de alimentos destinados ao público infantil de acordo com as regulamentações da legislação brasileira. J Health Sci Inst. 2015;33(4):351-9

25. Miranda LLS, Soares CS, Almeida CAF, Almeida DKC, Gregório EL, Amaral DA. Análise da rotulagem nutricional de pães de forma com informação nutricional complementar comercializados no município de Belo Horizonte, MG. HU Rev. 2017;43(3):211-7. https://doi.org/10.34019/1982-8047.2017.v43.2814 
26. Comelli C, Chiarini E, Prado SPT, Oliveira MA, Bergamini AMM. Avaliação microbiológica e da rotulagem de massas alimentícias frescas ou refrigeradas comercializadas em feiras livres e supermercados. Alim Nutr. 2011;22(2):251-8

27. Barros LO, Batista JS. Análise da rotulagem nutricional de barras de cereais light comercializadas em Fortaleza, Ceará. Rev Nutr Vigil Saúde. 2017;3(3):137-44. https://doi.org/10.18540/jcecvl4iss3pp0338-0344

28. Grandi AZ, Rossi DA. Avaliação dos itens obrigatórios na rotulagem nutricional de produtos lácteos fermentados. Rev Inst Adolfo Lutz. 2010;69(1):62-8.

29. Smith ACL, Almeida-Muradian LB. Rotulagem de alimentos: avaliação da conformidade frente à legislação e propostas para a sua melhoria. Rev Inst Adolfo Lutz. 2011;70(4):463-72.

30. Pereira JRP, Nomelini QSS, Pascoal GB, Rodrigues J, Pereira $P$. Análise de conformidade das informações apresentadas nos rótulos de barras de cereais e pães light. Link Rev Cient. 2014;1(9):137-55.

31. Yamashita AS, Carrijo KF. Avaliação da rotulagem de patês de diferentes marcas produzidos em indústrias com serviço de inspeção sanitária oficial comercializados no município de Uberlândia, Minas Gerais, Brasil. Enc Biosf Cent Cient Conhecer. 2014;10(19):271-83.

32. Santos MCL, Shinohara NKS, Pimentel RMM, Padilha MRDF. Rotulagem da goma de tapioca. J Environ Anal Prog. 2018;3(3):330-8. https://doi.org/10.24221/jeap.3.3.2018.2085.330-338

33. Kiszko KM, Martinez OD, Abrams C, Elbel B. The influence of calorie labeling on food orders and consumption: a review of the literature. J Community Health. 2014;39(6):1248-69. https://doi.org/10.1007/s10900-014-9876-0

34. Nadal J, Ferreira SMR, Costa IB, Schmidt ST. The principle of human right to adequate food and celiac disease: advancements and challenges. Demetra. 2013;8(3):411-23.

35. Ministério da Saúde (BR). Desmistificando dúvidas sobre alimentação e nutrição : material de apoio para profissionais de saúde. Brasília: Ministério da Saúde; 2016[acesso 20 ago 2020]. Disponível em: https: / /bvsms. saude.gov.br/bvs/publicacoes/desmistificando_duvidas_ sobre_alimentaçã o_nutricao.pdf

\section{Contribuição dos Autores}

Silva EBM, Vieira VRM, Gonçalves SARO, Takahashi JA, Araújo RLB - Concepção, planejamento (desenho do estudo), aquisição, análise, interpretação dos dados e redação do trabalho. Os autores aprovaram a versão final do trabalho.

Os autores informam não haver qualquer potencial conflito de interesse com pares e instituições, políticos ou financeiros deste estudo.

Licença CC BY-NC atribuição não comercial. Com essa licença é permitido acessar, baixar (download), copiar, imprimir, compartilhar, reutilizar e distribuir os artigos, desde que para uso não comercial e com a citação da fonte, conferindo os devidos créditos de autoria e menção à Visa em Debate. Nesses casos, nenhuma permissão é necessária por parte dos autores ou dos editores. 